Short communication

\title{
ETHNOBOTANY OF PLANTS USED AS INSECTICIDES, REPELLENTS AND ANTI- MALARIAL AGENTS IN JABITEHNAN DISTRICT, WEST GOJJAM
}

\author{
Abiyot Berhanu 1, Zemede Asfaw ${ }^{2}$ and Ensermu Kelbessa ${ }^{2}$ \\ 1Iinstitute of Biodiversity Conservation, Ecosystem Department, PO Box 30726 \\ Addis Ababa, Ethiopia. E-mail: abiyotmulu@yahoo.com \\ 2Department of Biology, Faculty of Science, Addis Ababa University \\ PO Box 1176, Addis Ababa, Ethiopia
}

\begin{abstract}
An ethnobotanical study on dants used for the prevention and treatment of malaria was conducted to document the indigenous knowledge particularly associated with the use and conservation of anti-malarial, insecticide and insect repellent medicinal plants. In this study, five sampling sites were selected based on the prevalence of malaria and availability of practitioners. Twenty five key informants were selected based on the comments from indigenous peoples, religious leaders and authorities. Moreover, 45 other informants were selected randomly by tossing a coin in their house or in working fields. Eight medicinal plants were found to be used as insecticides and insect repellents and 11 species as anti-malarial. Informants' consensus showed that 65.7 percent of the informants used Lepidium sativum for medicinal purposes followed by Croton macrostachyus (61.4 percent). The paired comparison showed that Allium sativum ranked first followed by Calpurnia aurea, $C$. macrostachyus, L. sativum and Phytolaca dodecandra for the treatment of malaria. On the other hand, the direct matrix ranking revealed that $C$. aurea ranked first followed by Dodonea angustifolia, $C$. macrostachyus, P. dodecandra and Gnidia involucrata. The study indicated that medicinal plants are at conservation risk because of suspected overuse and deforestation for settlement, agriculture and construction purposes. The introduction of proper management system in the society and encouraging practitioners to use medicinal plants sustainably can serve as a tool for the conservation of medicinal plants.
\end{abstract}

Key words/phrases: Indigenous knowledge, key informants, medicinal plants

\section{INTRODUCTION}

Traditional medicine is the sum total of the knowledge and practices, whether explicable or not, used in the diagnosis, prevention and elimination of physical, mental and/or social imbalance (WHO, 1987). It depends exclusively on practical experience and observations handed down from generation to generation verbally or in writing.

It is reported that 60 to 85 percent of the population in every country of the developing world has to rely on traditional medicine (Sofowora, 1982). It is estimated that more than 85 percent of the Ethiopian population doesn't enjoy the services and benefits of modern medicine (Amare Getahun, 1976; Dawit Abebe, 1986). Moreover, modern drugs are too expensive for the Ethiopian economy particularly the rural mass. Thus, the development of medicinal plants in primary health care not only will save the foreign exchange but also will aid in conserving our national heritage.

In Ethiopia, as well as around the world, traditional medicine mostly uses plants. Moreover, national product research is often based on ethnobotanical information and many of the drugs used today were developed from medicinal plants used by indigenous societies (Leonti et al., 2001). Despite this fact, many medicinal plants are threatened with extinction and indigenous cultures are being disrupted and destroyed (Martin, 1995; Zemede Asfaw, 2001). If this extinction and destruction continues in the present trend it will not be long that we lose very important part of our biodiversity, the totality of the diversity of genes, species, ecology and the different cultures (Abebe Demissie, 2001). Economic, agricultural and health conditions of people are dependent on these resources and native peoples have been stewards of 99 percent the world's genetic resources (Martin, 
1995). Moreover, there is an inextricable link between cultural and biological diversity.

On the other hand, in developing countries all over the world, large numbers of people die daily of preventable or curable health problems, for example malaria because of lack of even simple health care (Sofowora, 1982). Malaria control programs based on the application of insecticides (e.g., DDT) and anti-plasmodial agents are facing obstacles. This is partly due to the development of resistance to DDT by some species of mosquito. The other problem associated with the use of DDT is its deleterious effect on the environment. Thus, to cope with these kinds of problems alternative ways have to be developed by exploring and studying the accumulated knowledge and practical observation of indigenous people. For example, in malaria stricken countries of Africa quinine was, for a long time, a drug of choice for treating this disease, which was synthesized from the bark of Cinchona species (Rubiaceae). In Ethiopia, studies have shown that a number of medicinal plants are employed for the treatment of malaria, as larvicides, insecticides and mosquito repellents (Jansen, 1981; Gelahun Abate, 1989; Dawit Abebe and Ahadu Ayehu, 1993; Debela Hundie, 2001; Kebu Balemie, 2002).

In general, this study was conducted with the objective to document the indigenous knowledge particularly the knowledge associated with the use and conservation of anti-malarial, insecticides and insect repellent medicinal plants.

\section{MATERIALS AND METHODS}

\section{The study area}

The study was conducted in Jabitehnan District, West Gojjam. It lies approximately between latitudes $10^{\circ} 24^{\prime}$ and $10^{\circ} 56^{\prime} \mathrm{N}$ and longitudes $37^{\circ} 04^{\prime}$ and $3731^{\prime}$ E. It covers an area of $1230 \mathrm{~km}^{2}$ and it is situated $385 \mathrm{~km}$ northwest of Addis Ababa. According to the climatological data gathered for the last ten years (1991-2000), the average annual rainfall is $1047 \mathrm{~mm}$ and the major rain falls during June to August (MOA, 1982; NADC, 1983/4). The mean annual temperature ranges from $19^{\circ} \mathrm{C}$ to $24^{\circ} \mathrm{C}$. The highest temperature is registered to be $32.8^{\circ} \mathrm{C}$ in March and the lowest is $9.8^{\circ} \mathrm{C}$ in December and January.

The vegetation of the study area is a transition zone between Sudanian regional centre of endemism and the very lower part of the afromontane archipelago-like regional centre of endemism (White, 1983). It mainly consists of secondary scrub at higher altitudes and broadlived deciduous woodland at lower altitudes. However, at present only patches of secondary scrub and woodland vegetation are restricted to hills and river valleys. Trees of the genus Ficus (Moraceae) are the common forms around Geray and Menz districts and Fenote Selam Town. They appear in agricultural fields. The remnant vegetation is found following rivers and streams, rocky spots, hills and around churches. The vegetation is cleared for firewood, charcoal and agriculture.

\section{Population, disease prevalence and health services}

According to the census result of PHCC (2001), the population of Jabitehnan district is 237318 of which 50.06 percent are males and 49.9 percent are females. Among the total figure, 85.6 percent live in the rural areas while 14.4 percent live in the urban areas. The mother tongue is Amharic. There are three small to medium urban areas. One hospital and 11 health centres serve the people. Three of the health centres are private and the rest are governmental.

The ten most important health problems identified by the Jabitehnan district health service office (1998-2001) are, in their order of importance, malaria, respiratory health problems, intestinal parasites, gastritis, diarrhea, rheumatism, anaemia, skin ulcer, unknown fever and eye illness. Malaria occurs throughout the year and is the most prevalent disease on account of the suitable temperature, various small and medium bodies of water and the frequently used irrigation canal for breeding of mosquitoes. Malaria is more prevalent during the months of September through November and May and June provided that there is rainfall followed by warm temperature. In summer, humidity and flood do not support the growth of mosquito larvae to pupa and adult stages. Thus, malaria seldom occurs during July and August.

\section{Methods}

The study was conducted from July 15, 2001 to January 16, 2002. Accordingly, the study sites and informants were selected and ethnobotanical information was collected based on the methods given by Martin (1995) and Hoft et al. (1999). A field survey was made during the first filed visit and five study sites were selected based on the prevalence of malaria and availability of practitioners. The study sites are Fenote Selam town, Mankussa, Mebesh, Jimat, and Arba-etu Ensesa. 
Mankussa and Mebesh are located northeast and northwest of Fenote Selam at 9 and $8 \mathrm{kms}$, respectively. Whereas, the other two (Jimat and Geray) are situated southeast and south of Fenote Selam town 13 and $4 \mathrm{kms}$, respectively.

Seventy informants (25 key informants and 45 other informants) were selected. Key informants were selected based on comments and recommendations from religious leaders, elders and authorities. On the other hand, other informants were selected randomly from the community by tossing a coin and questioning every person in the house or in working fields whenever the head of the coin was up. Ethnobotanical data were collected using openended or semi-structured interviewing, direct matrix ranking and paired comparison (Martin, 1995; Hoft et al., 1999).

\section{RESULTS}

The use report about traditional medicinal plants for anti-malarial treatments, insecticides and insect repellents showed that Lepidium sativum (65.7 percent), Croton macrostachyus (61.4 percent), Allium sativum (58.6 percent) and Phytolaca dodecandra (58.4 percent) are widely used in the study area (Table 1$)$.

Moreover, ranking of all species based on three attributes (anti-malarial, insecticides and insect repellents) revealed that different usages exist among the society (Table 2). For example, based on the use report for insecticides only Cyphostema adenanthum is widely used followed by Calpurnia aurea and Capparis tomentosa. The use report for insect repellents only showed that A. sativum is commonly used followed by L. saivum and C. tomentosa.

On the other hand, the paired comparison of five selected medicinal plants used to treat malaria based on informants' consensus revealed that $A$. sativum, C. macrostachyus, and L. sativum ranked first, second and third, respectively (Table not shown here). However, the direct matrix ranking on five use criteria (building, medicine, firewood, washing and charcoal) showed that $C$. aurea, D. angustifolia and C. macrostachyus stood first, second and third, respectively (Table not shown here).

Table 1. Botanical names, local names and habit of medicinal plants used to treat malaria, as insecticides and insect-repellents, use reports, parts used and other uses (L, leaves; $R$, roots; $S$, seeds; $B$, bulbs; F, fruits; Br, barks; St, Stem; Sh, shrub; T, tree; H, herb, Ln, liana).

\begin{tabular}{|c|c|c|c|c|c|c|}
\hline Botanical name & Family & Local name & Habit & $\begin{array}{c}\text { Use report } \\
(\%)\end{array}$ & $\begin{array}{l}\text { Part } \\
\text { used }\end{array}$ & Other uses \\
\hline \multicolumn{7}{|l|}{ 1. Anti-malarial medicinal plants } \\
\hline Allium sativum $\mathrm{L}$. & Alliaceae & Nech shinkurt & $\mathrm{H}$ & 58.6 & $\mathrm{~B}$ & Pneumonia \\
\hline Calpurnia aurea (Lam.) Benth. & Fabaceae & Liyita & Sh & 10 & $\mathrm{~S}, \mathrm{~L}$ & Rabies \\
\hline Carica papaya $\mathrm{L}$. & Caricaceae & Papaya & $\mathrm{T}$ & 20 & $S$ & Abortion \\
\hline Dodonea angustifolia L. & Sapindaceae & Kitikta & Sh & 4.3 & $\mathrm{~F}$ & - \\
\hline Croton macrostachyus Hochst. ex Del. & Euphorbiaceae & Bissana & $\mathrm{T}$ & 61.4 & $\mathrm{~L}$ & Ring worm \\
\hline Gnidia involucrata Steud. ex A. Rich. & Thymelaceae & Beto & $\mathrm{H}$ & 11.4 & $\mathrm{R}$ & $\begin{array}{l}\text { STDS, } \mathrm{TB} \text {, Mental problem, } \\
\text { intestinal pain }\end{array}$ \\
\hline Gossypium barbadense $\mathrm{L}$. & Malvaceae & Tit & $\mathrm{H}$ & 1.4 & $\mathrm{Br}$ & - \\
\hline Jasminum abyssinicum Hochst & Oleaceae & Tembelel & $\mathrm{Ln}$ & 5.7 & $S, L$ & Rabies, insect repellent \\
\hline $\begin{array}{l}\text { Justicia scimperiana (Hochst. ex Nees) } \\
\text { T. Anders }\end{array}$ & Acanthaceae & Simiza & Sh & 21.4 & $\mathrm{~L}$ & Hepatitis \\
\hline Lepidium sativum $\mathrm{L}$. & Brassicaceae & Feto & $\mathrm{H}$ & 65.7 & S & Abdominal pain \\
\hline $\begin{array}{l}\text { Phytolaca dodecandra L'Herit } \\
\text { 2. Insecticides and insect repellents }\end{array}$ & phytolaccaceae & Endod & $\mathrm{Ln}$ & 58.4 & $\mathrm{~L}, \mathrm{R}$ & Intestinal parasites \\
\hline${ }^{1}$ Allium sativum $\mathrm{L}$. & * & * & * & * & * & * \\
\hline Calpurnia aurea (Lam.) Benth. & * & * & * & * & $\mathrm{L}$ & * \\
\hline Capparis tomentosa Lam. & Capparidaceae & Gumero & Sh & 18.6 & $\mathrm{R}, \mathrm{L}$ & - \\
\hline $\begin{array}{l}\text { Cyphostema adenanthum (Fresen.) } \\
\text { Descoings }\end{array}$ & Vitaceae & Etse-zewe & $\mathrm{H}$ & 11.4 & $\mathrm{R}, \mathrm{L}$ & - \\
\hline Jasminum abyssinicum Hochst & * & * & * & * & $\mathrm{L}$ & * \\
\hline${ }^{1}$ Lepidium sativum $\mathrm{L}$. & * & * & * & * & * & * \\
\hline Melia azedarch $\mathrm{L}$. & Meliaceae & Mimi-zaf & $\mathrm{T}$ & 15.7 & $\mathrm{~L}$ & Blood pressure \\
\hline Momordica foetida Schum. & Cucurbitaceae & Enkuriy & $\mathrm{H}$ & 14.3 & $\mathrm{R}, \mathrm{L}$ & - \\
\hline
\end{tabular}

Note: * see on the same table, ${ }^{1}$ not used as insecticides. 
Table 2. Ranks of all species used to treat malaria, as insecticides and repellents based on percentage of use reports for each attribute.

\begin{tabular}{lccc}
\hline Botanical name & \multicolumn{3}{c}{ Ranks } \\
\cline { 2 - 4 } & Mosquito repellent & Insecticide & Anti-malarial \\
\hline Allium sativum L. & $1^{\text {st }}$ & - & $1^{\text {st }}$ \\
Calpurnia aurea (Lam.) Benth. & $7^{\text {th }}$ & $2^{\text {nd }}$ & $8^{\text {th }}$ \\
Capparis tomentosa Lam. & $3^{\text {rd }}$ & $3^{\text {rd }}$ & - \\
Carica papaya L. & - & - & $6^{\text {th }}$ \\
Croton macrostachyus Hochst. ex Del. & - & - & $4^{\text {th }}$ \\
Cyphostema adenanthum (Fresen.) Descoings & $6^{\text {th }}$ & $1^{\text {st }}$ & - \\
Dodonea angustifolia L. & - & - & $10^{\text {th }}$ \\
Gnidia involucrata Steud. ex A. Rich. & - & - & $7^{\text {th }}$ \\
Gossypium barbadense L. & - & - & $11^{\text {th }}$ \\
Jasminum aby ssinicum Hochst & $8^{\text {th }}$ & $4^{\text {th }}$ & $9^{\text {th }}$ \\
Justicia scimperiana (Hochst. ex Nees) T. Anders & - & - & $5^{\text {th }}$ \\
Lepidium sativum L. & $2^{\text {nd }}$ & - & $3^{\text {rd }}$ \\
Melia azedarch L. & $4^{\text {th }}$ & $6^{\text {th }}$ & - \\
Momordica foetida Schum. & $5^{\text {th }}$ & $5^{\text {th }}$ & - \\
Phytolaca dodecandra L'Herit & - & - & $2^{\text {nd }}$ \\
\hline
\end{tabular}

\section{DISCUSSION}

\section{Prevention and treatment}

In the study area traditional medicinal diagnosis is essentially based on systematic interviewing and Physical examination (Dawit Abebe, 1986; Abiyot Berhanu, 2002). Besides, if the disease is very serious and the healer thinks that it is the result of evil spirits, magical performances are often carried out to know it clearly. Churches and some peoples frequently state that this method of diagnosis is against the will of God. After all, if the healer is unable to ascertain the type of disease, the patient is sometimes referred to the nearby health institution either to bring the result of the diagnosis or to be treated there. The other way often practiced is referring the patient to more knowledgeable traditional healer with strict warning not to tell the name of the healer who referred him. The diagnosis of malaria (Noba) is often simple: intermittent fever and shivering recognized as symptoms of malaria (Dawit Abebe, 1986).

The overall conditions of the patient are taken into consideration while measuring out dosages. The major factors that determine whether the treatment is to be given are age, physical fitness, stage of illness, pregnancy and presence or absence of any disease other than the disease to be treated (Dawit Abebe, 1986; 1996; Debela Hundie, 2001). For example, a drug against malaria, which is prepared from Gnidia involucrata or Phytolaca dodecandra, is not administered for a patient with hepatitis. On the other hand, a drug prepared from $P$. dodecandra is not administered to babies or old people, as it is lethal. Drugs that are given through the mouth and the nose are not usually administered to pregnant women unless the patient is in critical situation.

Prevention of malaria (as well as other diseases) is commonly practiced by indigenous people using traditional insecticides and insect repellent plants. Particularly, insect repellents are widely employed in the study area. For example, A sativum is the most widely used mosquito repellent followed by L. sativum. The infusion prepared from those plants is applied on exposed body parts so as to directly attack mosquitoes and other pathogenic insects. Moreover, repellents or liquid preparations are sprayed all over the walls of the house and this method is employed in killing insects. Some of the commonly used insecticides include Cyphostema adenanthum, Calpurnia aurea and Capparis tomentossa. Smoking and growing medicinal plants near the entrances of the fence is also practiced as insect repellents though detailed information is lacking to how it works.

The paired comparison of the five species based on their anti-malarial importance only showed that A. sativum is most preferred followed by $C$. macrostachyus even though the latter is more widely used for the treatment of other health problems. Lepidium sativum ranked third for prevention and treatment of malaria though it is the first in treating different health problems. This is because most of the respondents used in the paired comparison were healers and they are less interested in commonly known medicinal plants by indigenous people. Phytolaca dodecandra and C. aurea are also known for their poisonous properties 
and the indigenous people and healers are well aware of their lethal actions.

\section{Conservation of medicinal plants}

The direct matrix ranking for randomly selected five medicinal plants used to treat malaria on five uses criteria showed that medicinal plants are widely harvested for different purposes. This is particularly true for C. aurea and D. angustifolia. Thus, indigenous people use those species for charcoal and fire wood. However, G. involucarta is extensively used for medicinal purposes by healers only with very little use as fire wood by other people. Generally, the direct matrix ranking shows that those medicinal plants are at conservation risk because of overexploitation and additional uses for different activities.

\section{CONCLUSIONS AND RECOMMENDATIONS}

The number of medicinal plants reported for the prevention and treatment of malaria is a good indicator of the potential that exists locally so long as scientific procedure is added to the indigenous knowledge. In this connection, it is important to develop the indigenous knowledge by focusing on the most popular plants used against malaria including through extraction and developing phytomedicines. In view of the good number of plants used as insecticides and insect repellents, this work can concentrate more on those as prevention is most desired than cure and this is very relevant in the case of malaria, which is a devastating disease in the study area. Thus, in view of seriousness of malaria in the study area and existence of medicinal plants for the prevention and control of it, research must be enhanced to test activities of those species widely used by the society namely $A$. satioum, $C$. macrostachyus, L. sativum, P. dodecandra, C. adenanthum and C. aurea. Moreover, a further study on the conservation and sustainable use of medicinal plants is recommended.

\section{ACKNOWLEDGEMENTS}

The authors would like to acknowledge the Swedish Agency for Research Cooperation with Developing Countries (SAREC), the National Herbarium, the Department of Biology and Geology, the Jabitehnan District Peoples and others which directly and indirectly offered their help during the study. The cost of this study was partly covered by a project grant of Dr. Zemede Asfaw for Ethnobotanical Study of Insecticides, Anti-malarial and Mosquito Repellent Plants.

\section{REFERENCES}

1. Abebe Demissie (2001). Biodiversity conservation of medicinal plants, problems and prospects. In: Proceedings of the National Workshop on Biodiversity Conservation and Sustainable use of Medicinal Plants in Ethiopia, pp. 56-64. Addis Ababa.

2. Abiyot Berhanu (2002). Use and conservation of human traditional medicinal plants by indigenous people in Jabitehnan District, West Gojjam. MSc thesis (unpublished).

3. Amare Getahun (1976). Some common medicinal and poisonous plants used in Ethiopian Folk Medicine (working manual).

4. Dawit Abebe (1986). Traditional medicine in Ethiopia: the attempts being made to promote it for effective and better utilization. SINET: Ethiop. J. Sci. 9:61-69.

5. Dawit Abebe (1996). The role of herbal remedies and the approach towards their development. In: Proceedings of the Workshop on Development and Utilization of Herbal Remedies in Ethiopia, pp. 2838. Ethiopian health and nutrition research, Addis Ababa.

6. Dawit Abebe and Ahadu Ayehu (1993). Medicinal plants and enigmatic health practices of northern Ethiopia. B.S.P.E., Addis Ababa.

7. Debela Hundie (2001). Use and management of traditional plants by indigenous people of Boosat District Welenchiti Area. MSc thesis (unpublished).

8. Gelahun Abate (1989). Etse Debdabe (Ethiopian traditional medicine). Research and publication office, Addis Ababa (in Amharic).

9. Hoft, H., Barik, S.K. and Lykke, A.M. (1999). Quantitative ethnobotany. Applications of multivariate and statistical analysis in ethnobotany. Division of ecological sciences, UNESCO.

10. Jansen, P.C.M. (1981). Spices, Condiments and Medicinal Plants in Ethiopia. Centre for agricultural publishing and documentation, the Netherlands.

11. Kebu Balemie (2002). Indigenous medicinal plant utilization and management by Kereyu Pastoralists in Fentalle, Eastern Shewa. MSc thesis (unpublished).

12. Leonti, M., Vibrans, H., Sticher, O. and Heinrich, H. (2001). Ethnopharmacology of the Popoluca, 
Mexico: an evaluation. Journal of Pharmacy and Pharmacology 53(12):1653-1669.

13. Martin, G.J. (1995). Ethnobotany: A Methods Manual. Chapman and Hall, London.

14. MOA (1982). Summaries of rainfall and temperature data. Agricultural development: Agronomy division Ministry of Agriculture, The Provisional Military of Socialist Ethiopia, Addis Ababa.

15. NADC (1983/84). Northeast Agricultural Development Corporation. Birr-Beles State Farm Production Program, Operation and Capital Budget. Planning and programming service Addis Ababa.

16. PHCC (2001). Amhara Region III Statistical Report. Population and Housing Census Commission, Central Statistical Authority, Federal and Democratic Republic of Ethiopia, Addis Ababa.
17. Sofowora, A. (1982). Medicinal Plants and Traditional Medicine in Africa. John Willey and Sons Ltd, New York.

18. White, F. (1983). The vegetation of Africa. A descriptive Memoir to Accompany the UNESCO Vegetation Map of Africa. National Resource Research, Paris.

19. WHO (1987). Guideline for the Management of Severe and Complicated Malaria in Ethiopia. National Programme for the Control of Malaria and other Vector Born Health Problems. Ministry of Health, Addis Ababa.

20. Zemede Asfaw (2001). The role of home gardens in production and conservation of medicinal plants. In: Proceedings of the National Workshop on Biodiversity Conservation and Sustainable use of Medicinal Plants in Ethiopia, pp. 76-79. Addis Ababa. 